\title{
Effects of water availability gradient on biomass allocation of dominant plants in Inner Mongolia steppe
}

\author{
Yongjie Liu ${ }^{1}$, Fujiang $\mathrm{Hou}^{1}$, and Zhenqing $\mathrm{Li}^{2}$ \\ ${ }^{1}$ Lanzhou University \\ ${ }^{2}$ Institute of Botany Chinese Academy of Sciences
}

July 28, 2020

\begin{abstract}
1 Extreme events such as extreme drought and rainfall are predicted to be more frequent under ongoing climate change. Biomass allocation is an important strategy for plants to respond to such changes. However, few studies explored the effects of water availability on biomass allocation of dominant plants in Inner Mongolia steppe in China. 2 A controlled experiment was conducted by treating four perennial plant species (Leymus chinensis, Stipa grandis, Artemisia frigida and Potentilla acaulis) with eight levels of water availability, which was selected based on the local annual mean precipitation, simulating rainfall scenarios facing climate change. 3 Water availability significantly affected the aboveground biomass, belowground biomass, total biomass and the ratio of belowground biomass and aboveground biomass of plants, and these effects were modified by species. Our results indicated that plants could modify their biomass allocation strategies to adapt to the gradient of water availability. 4 Climatic factors such as precipitation and temperature always co-vary, thus responses of plants to more complicated climate change (e.g. the joint variation of temperature and rainfall) should be further explored in order to better understand grassland management and restoration under climate change.
\end{abstract}

\section{Introduction}

Climate change, such as extreme drought and rainfall, varies spatially and temporally (IPCC 2007; Benestad et al., 2012). Such changes significantly affect plants. For example, global warming caused substantial damage on plants due to the drought and heat stress (Lipiec et al., 2013; Elst et al., 2017). Rainfall variation impacted terrestrial ecosystems since water limited plant growth, reproduction and productivity (De Boeck et al., 2017). Resource allocation is a vital strategy for plants to respond to the environmental variation (Harper et al., 1970; Mokany et al., 2006). For instance, the energy originated from photosynthesis of a plant can be allocated between aboveground and belowground organs such as leaves and roots. The former enables plants to do photosynthesis, while the latter could store resources for plants to grow. Biomass allocation between aboveground and belowground organs is known as root: shoot ratio (i.e. R: S, Guo et al., 2007). Several studies explored the effects of climate change on plants (Bai et al., 2008; Gonzalez-Dugo et al., 2010; Knapp et al., 2008, 2017). However, contrasting results were found in plant growth and productivity, which merits further research.

Previous studies found that abiotic factors such as temperature and rainfall impacted the R: S (Fay et al., 2003; Yang et al. 2018). For example, rainfall affected the biomass allocation and the belowground ecological processes of plants (Fay et al., 2003), where plants allocated more biomass to roots in order to explore soil water when they growing on dry conditions (Bray 1963), while they allocated more biomass to shoots in order to seize the light when plants growing on wet conditions (Villar et al., 1998). Moreover, higher levels of soil heterogeneity increased R: S (Michael et al., 2004; Wu et al., 2014; Liu et al., 2017a), where plants growing on patches with low quality grew more roots into their neighboring patches with high quality (Liu et al., 2017b, Liu et al., 2019). However, effects of biotic factors on biomass allocation were complicated. 
Some studies found that R: S was not affected by the aboveground competition (Zhang et al., 2014), and belowground competition did not increase the biomass allocation to roots. However, some other studies found that R: S was influenced by the type of grasslands (Coupland 1980) and plant growth (Gedroc et al., 1996; James et al., 2003). Thus, further studies are needed.

Climate changes such as extreme drought are predicted to be more frequency (Benestad et al., 2012; Felton et al., 2019). Thus, it is crucial to explore the effects of such changes on plant productivity and their allocation strategies (Bai et al., 1997; Cai et al., 2005 Lv et al., 2016). Here an experiment was conducted to explore the effects of water availability on biomass allocation of plants at the population scale, where 4 plant species (Leymus chinensis, Stipa grandis, Artemisia frigida, Potentila acaulis ) that dominant at degraded grasslands in Inner Mongolia steppe were treated with 8 levels of water additions, which was set to simulate the rainfall scenarios in the face of climate change. Note that the degradation of grasslands in Inner Mongolia are caused by activities such as grazing (Liu et al., 2006, 2007), where L. chinensis and $S$. grandis are the two dominant species in the lightly degraded grasslands ( $\mathrm{Li}$ et al., 2005), while A. frigida and $P$. acaulis are the dominant species in the heavily degraded grasslands. We expect that species at the lightly degraded grasslands will be more sensitive to the rainfall variation since they grow fast and tend to have relatively larger plant sizes, while species at the heavily degraded grasslands could withstand the water additions as they tend to grow slowly and to have relatively smaller plant sizes (Ma 2015). Specially, the biomass allocation between the aboveground and belowground organs of L. chinensis and S. grandis are expected to vary with water availability; while water availability is expected to not impact the biomass allocation of $A$. frigida and $P$. acaulis . This study can improve our understanding of grassland management and the restoration of degraded grasslands, especially in the face of climate change.

\section{Materials and Methods}

\subsection{Study field}

This study was conducted in Inner Mongolia steppe in China ( $\left.43^{\circ} 33^{\prime} \mathrm{N}, 116 \mathrm{deg} 40^{\prime} \mathrm{E}\right)$. The mean elevation of the location is $1225 \mathrm{~m}$ (range: $1200 \mathrm{~m}-1250 \mathrm{~m}$ ). This location is characterized by mild humid summer and dry clod winter, which is temperate semi-arid continental monsoon climate. Annual mean temperature is around $-1.1 \operatorname{deg} \mathrm{C}-0.2 \mathrm{degC}$. There is a large temperature difference within a year $(-21.4 \mathrm{deg} \mathrm{C}$ in the coldest month in January, while $18.5 \mathrm{deg}$ in the warmest month in July). The frost-free period is around 100 days in a year. The annual mean precipitation between 1980 and 2000 is $350 \mathrm{~mm}$, where the precipitation mainly occurs in June and August, and the amount of rainfall during this period is around $80 \%$ of the amount of rainfall in the whole year. The site is dominated by dark chestnut soil (Jia et al., 2005; Lisetskii and Rodionova 2015). The dominant species are Dauri-Mongolian species such as L. chinensis, S. grandis, A. frigida and P. acaulis ( $\mathrm{Li}$ and $\mathrm{Li} 2002$ ).

\subsection{Experimental design}

From May 2000 to October 2001, an experiment was conducted to explore the responses of the 4 target plant populations to 8 levels of water additions, which were set according to the local annual mean precipitation during 1980-2000 (i.e. $350 \mathrm{~mm}$ ), and they were $170 \mathrm{~mm}, 250 \mathrm{~mm}, 300 \mathrm{~mm}, 350 \mathrm{~mm}, 525 \mathrm{~mm}, 595 \mathrm{~mm}$, $665 \mathrm{~mm}$ and $700 \mathrm{~mm}$, respectively. This study aims to explore the effect of water amount on plants, not to mimic the local rainfall pattern. Thus, water was added daily to each treatment, and the amount of water was determined by dividing the total amount of rainfall in each pattern by the total growing days. Plants grew in pots with diameter $30 \mathrm{~cm}$. There were three replications of each treatment for each species, ending with 19 pots in total. For L. chinensis, seeds were randomly sown in the pots in early May 2000, and four individuals with the similar size in each pot were kept after germination, and the rest were removed manually. For $S$. grandis, four ramets with similar size were transplanted from the nearby field to each pot in later May 2000 (similar sowing was done here in early May 2000, but the germination rate was too low). For $A$. frigida and $P$. acaulis, plants were dug out from the nearby field, and ramets were then separated into similar size. Four of them were transplanted into each pot in early May 2001. All the plants were grown under natural condition before applying treatments, which occurred from 10 June to 10 September 2001. 
At the end of the experiment, all the plants in each pot were washed out from their growing soils, and then separated into aboveground group (AG) and belowground group (BG), where soil surface is the baseline. For L. chinensis and S. grandis, AG included leaves and stems, while BG included roots and rhizomes. For A. frigida, AG included leaves, flowers and stems, while BG included roots. For P. acaulis, AG included leaves and stems, while BG included roots. All the biomasses were oven-dried at $65 \mathrm{degC}$ to constant weight and weighted.

\subsection{Statistical analysis}

In each pot: aboveground biomass (or belowground biomass) was calculated by dividing the aboveground biomass (or belowground biomass) of the four individuals by the pot surface area (i.e. $3.14 \times 0.3 \mathrm{~m} \times 0.3$ $\mathrm{m}$ ). Total biomass was calculated by adding the aboveground biomass and belowground biomass, converted to $\mathrm{g} \mathrm{m}^{-2}$ via dividing by pot surface area. Ratio of belowground biomass and aboveground biomass (R: S) was calculated by dividing belowground biomass by aboveground biomass.

Curve estimations were applied to explore the relationship between water availability and total biomass, aboveground biomass, belowground biomass and R: S ratio. Then, linear or non-linear regressions were conducted to test the equations of these relationships, where equation with a larger $\mathrm{R}^{2}$ and a significant $\mathrm{p}$ value is a better one. All statistics were done with SPSS 21.0.

\section{Results}

Water availability significantly affected total biomass, aboveground biomass, belowground biomass and R: S ratio of plants, which were modified by species (Table 1-4; Fig. 2-5).

(1) For L. chinensis : increasing water availability significantly increased its total biomass (Fig. 2a) and R: S ratio (Fig. 5a). The latter mainly derived from the increased belowground biomass (Fig. 4a), and aboveground biomass firstly increased and then decreased after reaching to a peak (Fig. 3a).

(2) For S. grandis : increasing water availability increased firstly and then decreased its total biomass (Fig. 2b), forming a unimodal pattern. Similar patterns were found in aboveground biomass (Fig. 3b) and belowground biomass (Fig. 4b). However, increasing water availability did not impact its R: S ratio (Fig. $5 b)$.

(3) For A. frigida : increasing water availability increased its total biomass (Fig. 2c) and belowground biomass (Fig. 4c). Aboveground biomass (Fig. 3c) and R: S ratio (Fig. 5c) followed a unimodal pattern.

(4) For P. acaulis : increasing water availability increased its total biomass (Fig. 2d), aboveground biomass (Fig. 3d) and belowground biomass (Fig. 4d). However, it decreased the R: S ratio (Fig. 5d).

\section{Discussions}

In this study, we found that increasing water availability increased the total biomass of three of the four target species. However, the total biomass of $S$. grandis followed a unimodal pattern with increasing water availability. Interestingly, the four target plant species adopted different strategies to deal with water availability, where with increasing water availability, $\mathrm{R}: \mathrm{S}$ of species $L$. chinensis and A. frigida followed an unimodal pattern, where the lowest points were $83 \mathrm{~mm}$ and $475 \mathrm{~mm}$, respectively. L. chinensis has strong forage ability as a rhizomatous species (Wang et al. 2004), which enables this species to allocate more biomass to its roots when growing on wet conditions (Yang and Yang 1998). R: S of species P. acaulis decreased, while R: S of species $S$. grandis was not significantly affected. Our findings are in line with previous studies that plants modified their biomass allocation strategies to adapt to their growing conditions (Schmid 1987; Enquist et al., 2002). We expected that species dominant in lightly and heavily degraded grasslands responded differently to the water availability. In line with our expectation, $\mathrm{R}: \mathrm{S}$ of $A$. frigida and $P$. acaulidecreased, to some extent, with the increasing water availability (Fig. 5c-d). Such findings are also consistent with the results of species such as Salix psammophila, Hedysarum leave, Artemisia ordosica and Caragana korshinskii in the previous studies (Dong et al., 1999; Xiao et al., 2001). However, the responses 
of R: $\mathrm{S}$ of $L$. chinensis and $S$. grandis to increasing water availability in this study indicate that some other strategies merit further research.

A unimodal relationship between water availability and total biomass was found in species S. grandis and A. frigida, where the highest points were $519 \mathrm{~mm}$ and $850 \mathrm{~mm}$, respectively. In other words, increasing water availability firstly increased and then decreased their total biomass when the rainfall became detrimental, which might be caused by a lack of oxygen since it is fatal to the root respiration (Lambers and Steingrover 1978). Such result indicates that species $S$. grandis and A. frigida could tolerate dry conditions, while the latter species has a much wider range of water availability. Under extreme wet conditions, both $S$. grandis and A. frigida decreased their total biomass, while the former reduced both its aboveground biomass (Fig. $3 \mathrm{~b}$ ) and belowground biomass (Fig. 4b), while the latter decreased only its aboveground biomass (Fig. 4c). Such difference could be a key driver of species coexistence (Sanaei et al., 2018). Species adopted different biomass allocation strategies to respond to water availability, suggesting that fitness of some species such as $S$. grandis is not significantly affected by the water availability, and such dominant species could further impact the community structure and ecosystem functioning. However, increasing water availability inhibited the growth and productivity of species such as $A$. frigida and $P$. acaulis, but improved the plant fitness through reducing the availability of the grasslands (Neilson 1995).

\section{Conclusions}

Water availability significantly increased the total biomass of plant species. Remarkably, water availability affected the biomass allocation of plants, which were modified by species. Generally, increasing water availability did not impact or increased R: S of plant species that dominant in the lightly degraded grasslands, while it decreased R: S of plant species that dominant in the heavily degraded grasslands. Thus, biomass allocation of plants is an important indicator to explore the responses of plants to climate change, which should be further explore by considering more complicated conditions such as jointed effects of temperature and precipitation.

\section{Acknowledgements}

We acknowledge Jinhua Li for the experimental assistance. The authors declare no conflict of interest. This research was supported by the National Key Research and Development Program of China (2019YFC0507704), and the National Natural Science Foundation of China (41571505). Yongjie Liu holds a start-up fund from Lanzhou University (508000-561119213). The authors declare no conflict of interest.

\section{Authors' contributions}

LZ designed and conducted the study. LY and LZ analysed the data. LY, HF and LZ discussed the data and contributed critically to the drafts.

\section{Data availability statement}

Data from this manuscript will be available through Nicholas A. Levis' Dryad account once this manuscript be published.

\section{References}

Bai Y, Xu Z. 1997. A model of aboveground biomass of Aneurolepidium chinense community in response to seasonal precipitation. Acta Prataculturae Sinica 6:1-6.

Bai Y, Wu J, Xing Q, Pan Q, Huang J, Yang D, Han X. 2008. Primary production and rain use efficiency across a precipitation gradient on the Mongolia plateau. Ecology 89:2140-2153.

Benestad RE, Nychka D, Mearns LO. 2012. Spatially and temporally consistent prediction of heavy precipitation from mean values. Nature Climate Change 2:2969-2980.

Bray J. 1963. Root production and the estimation of net productivity. Canadian Journal of Botany 41:65-72. 
Cai X, Li Z, Chen Z, Wang Y, Wang S, Wang Y. 2005. The relationship between aboveground biomass and precipitation on Stipa grandissteppe in Inner Mongolia. Acta Ecologica Sinica 25:1657-1662.

Coupland RT. 1980. Grassland ecosystems of the world. Journal of Ecology 68:1097-1098.

De Boeck HJ, Bloor JMG, Kreyling J, Ransijn JCG, Nijs I, Jentsch A, Zeiter M. 2017. Patterns and drivers of biodiversity-stability relationships under climate extremes. Journal of Ecology 106:890-902.

Dong M, Alateng B, Xing X, Wang Q. 1999. Genet features and ramet population features in the rhizomatous grass species Psammochloa villosa. Acta Phytoecologica Sinica 23:302-310.

Enquist BJ, Niklas J. 2002. Global allocation rules for patterns of biomass partitioning in seed plants. Science 295:1517-1520.

Elst EM, De Boeck HJ, Vanmaele L, Verlinden M, Dhliwayo P, Nijs I. 2017. Impact of climate extremes modulated by species characteristics and richness. Perspectives in Plant Ecology, Evolution and Systematics 24:80-92.

Fay PA, Carlisle JD, Knapp AK, Blair JM, Collins SL. 2003. Productivity responses to altered rainfall patterns in a C4-dominanted grassland. Oecologia 137:245-251.

Felton AJ, Slette IJ, Smith MD, Knapp AK. 2019. Precipitation amount and event size interact to reduce ecosystem functioning during dry years in a mesic grassland. Global Change Biology 26:658-668.

Gedroc JJ, McConnaughay DM, Coleman JS. 1996. Plasticity in root/shoot partitioning: optimal, ontogenetic, or both? Functional Ecology 10:44-50.

Gonzalez-Dugo V, Durand JL, Gastal F. 2010. Water deficit and nitrogen nutrition of crops. A review. Agronomy for Sustainable Development 30:529-544.

Guo W, Li B, Zhang X, Wang R. 2007. Architectural plasticity and growth responses of Hippophae rhamnoides and Caragana intermediaseedlings to stimulated water stress. Journal of Arid Environments 69:385399.

Harper JL, Ogden J. 1970. The reproductive strategy of higher plants: I. The concept of strategy with special reference to Senecio vulgaris L. Journal of Ecology 58:681-698.

IPCC 2007. The Physical Science Basis: Summary for Policymakers. Contribution of WG1 to the Fourth Assessment Report of the Intergovernmental Panel on Climate Change.

James SE, Partel M, Wilson SD, Peltzer DA. 2003. Temporal heterogeneity of soil moisture in grassland forest. Journal of Ecology 91:234-239.

Jia B, Zhou G, Wang F. Wang Y. 2005. Soil respiration and its influencing factors at grazing and fenced typical Leymus chinensis Steppe, ei Monggol. Environmental Science 26:1-7.

Knapp AK, Beier C, Briske DD, Classen AT, Luo Y, Reichstein M, Smith MD, Smith SD, Bell JE, Fay PA, Heisler JL, Leavitt SW, Sherry R, Smith B, Weng E. 2008. Consequences of more extreme precipitation regimes for terrestrial ecosystems. BioScience 58:811-821.

Knapp AK, Ciais P, Smith MD. 2017. Reconciling inconsistencies in precipitation-productivity relationships: implications for climate change. New Phytology 214:40-47.

Lambers H, Steingrover E. 1978. Efficiency of root respiration of a flood-tolerant and a flood-intolerant Senecio species as affected by low oxygen tension. Physiologia Plantarum 42:179-184.

Li J, Li Z. 2002. Clonal morphological plasticity and biomass allocation pattern of Artemisia frigida and Potentilla acaulis under different grazing intensities. Acta Phytoecologica Sinica 26:435-440. 
Li J, Li Z, Ren J. 2005. Effect of grazing intensity on clonal morphological plasticity and biomass allocation patterns of Artemisia frigida and Potentilla acaulis in the Inner Mongolia steppe. New Zealand Journal of Agricultural Research 48:57-61.

Lipiec J, Doussan C, Nosalewicz A, Kondracka K. 2013. Effect of drought and heat stresses on plant growth and yield: a review. International Agrophysics 27:463-477.

Liu Y, Bortier MF, De Boeck HJ, Nijs I. 2017a. Root distribution responses to three-dimensional soil heterogeneity in experimental mesocosms. Plant and Soil 421:353-366.

Liu Y, De Boeck HJ, Wellens MJ, Nijs I. 2017b. A simple method to vary soil heterogeneity in three dimensions in experimental mesocosms. Ecological Research 32:27-295.

Liu Y, De Boeck HJ, Li ZQ, Nijs I. 2019. Unimodal relationship between three-dimensional soil heterogeneity and plant species diversity in experimental mesocosms. Plant and Soil 436:397-411.

Liu Z, Li Z, Dong M, Johnston B. 2006. The response of a shrub-invaded grassland on the Inner Mongolia steppe to long-term grazing by sheep. New Zealand Journal of Agricultural Research 49:163-174.

Liu Z, Li Z, Dong M, Ivan N, Jan B, El-Bana MI. 2007. Small-scale spatial associations between Artemisia frigida andPotentilla acaulis at different intensities of sheep grazing. Applied Vegetation Science 10:139-148.

Lisetskii FN, Rodionova ME. 2015. Transformation of dry-steppe soils under long-term agrogenic impacts in the area of ancient Olbia. Eurasian Soil Science 48:347-358.

Lv X, Zhou G, Wang Y, Song X. 2016. Sensitive indicators of zonal Stipa species to changing temperature and precipitation in Inner Mongolia grassland, China. Frontier in Plant Science 7:73.

Ma G. 2015. Responses of plant phenology to changes of precipitation regimes in a temperate steppe in Inner Mongolia, China. Master dissertation, Henan University.

Mokany K, Raison RJ, Prokushkin AS. 2006. Critical analysis of root: shoot ratios in terrestrial biomes. Global Change Biology 12:84-96.

Michael HJ, Elizabeth JA. 2004. The effects of environmental heterogeneity on root growth and root/shoot partitioning. Annual of Botany 94:1-8.

Neilson RP. 1995. A model for predicting continental-scale vegetation distribution and water balance. Ecological Applications 5:362-497.

Sanaei A, Chahouki MAZ, Ali A, Jafari M, Azarnivan H. 2018. Abiotic and biotic drivers of aboveground biomass in semi-steppe rangelands. Science of the Total Environment 615:895-905.

Schmid B. 1987. Clonal integration and population structure in perennials, effects of severing rhizome connection. Ecology 68:2016-2022.

IBM Corp. 2012. IBM SPSS statistics for windows (version 21.0). Armonk, New York.

Villar R, Veneklaas EJ, Jordano P, Lambers H. 1998. Relative growth rate and biomass allocation in 20 Aegilops (Poaceae) species. New Phytology 140:425-437.

Wang Z, Li L, Han X, Dong M. 2004. Do rhizome severing and shoot defoliation affect clonal growth of Leymus chinensis at ramet population level? Acta Oecologica 26:25-260.

Wu G, Zhang Z, Wang D, Shi Z, Zhu Y. 2014. Interactions of soil water content heterogeneity and species diversity patterns in semi-arid steppes on the Loess Plateau of China. Journal of Hydrology 519:1362-1367.

Xiao C, Zhang X. 2001. Response of seedlings of three dominant shrubs to climate warming in Ordos Plateau. Acta Botanica Sinica 43:736-741. 
Yang C, Yang L. 1998. Plasticity of clonal modules of Leymus chinensis in response to different environments. Chinese Journal of Applied Ecology 9:265-268.

Yang Y, Dou Y, An S, Zhu Z. 2018. Abiotic and biotic factors modulate plant biomass and root/shoot (R/S) ratios in grassland on the Loess Plateau, China. Science of the Total Environment 636:621-631.

Zhang H, Shen X, Li F, Guan S, Zhou D. 2014. Partitioning of organic carbon in Leymus chinensis grassland ecosystems with different population densities in Songnen grassland, China. Chinese Journal of Ecology $33: 2281-2287$.

Table 1 Results of the curve estimation of the relationship between water additions and total biomass, aboveground biomass, belowground biomass and R: S ratio (i.e. the ratio of aboveground biomass and belowground biomass) of species Leymus chinensis with linear, quadratic, power and exponential equations, where $\mathrm{R}^{2}$, F, Df1, Df2, significance, constant, b1 and b2 were showed. A larger $\mathrm{R}^{2}$ with a significant value is a better estimation, which is marked in red

Leymus

chi-

nensis Total Total Total Total Total Total Total Total AbovegrodibdvegrodibdvegroAbdvegroAbd Equationbiomass biomass biomass biomass biomass biomass biomass biomass biomass biomass biomass biomass biom

\begin{tabular}{|c|c|c|c|c|c|c|c|c|c|c|c|c|c|}
\hline & $\mathrm{R}^{2}$ & $\mathrm{~F}$ & Df1 & Df2 & Sig. & \multicolumn{2}{|c|}{ Constantb1 } & \multirow[t]{2}{*}{$\mathrm{b} 2$} & \multirow{2}{*}{$\begin{array}{l}\mathrm{R}^{2} \\
0.674\end{array}$} & \multirow{2}{*}{$\begin{array}{l}\mathrm{F} \\
45.522\end{array}$} & \multirow{2}{*}{$\begin{array}{l}\text { Df1 } \\
1\end{array}$} & \multirow{2}{*}{$\begin{array}{l}\text { Df2 } \\
22\end{array}$} & \multirow{2}{*}{$\begin{array}{l}\text { Sig. } \\
<0\end{array}$} \\
\hline Linear & 0.601 & 33.178 & 1 & 22 & $<0.001$ & 26.031 & 0.198 & & & & & & \\
\hline \multicolumn{2}{|c|}{ Quadratiø.615 } & 16.744 & 2 & 21 & $<0.001$ & 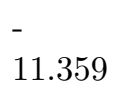 & 0.404 & & 0.675 & 21.813 & 2 & 21 & \\
\hline Power & 0.624 & 36.437 & 1 & 22 & $<0.001$ & 0.925 & 0.786 & & 0.655 & 41.853 & 1 & 22 & \\
\hline Expont & 1t0a387 & 31.257 & 1 & 22 & $<0.001$ & 43.239 & 0.002 & & 0.633 & 37.963 & 1 & 22 & \\
\hline $\begin{array}{l}\text { Leymu } \\
\text { chi- } \\
\text { nensis } \\
\text { Equati }\end{array}$ & & & \multicolumn{3}{|c|}{ 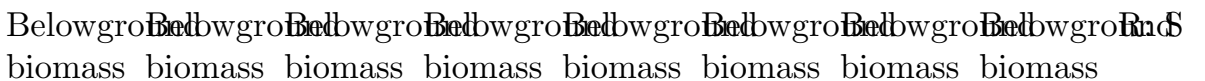 } & $\begin{array}{l}\text { obredbwg } \\
\text { biomas }\end{array}$ & $\begin{aligned} \text { olberbw } \\
\text { bioma }\end{aligned}$ & & oRan & R: S & $\mathrm{R}: \mathrm{S}$ & R: S & \\
\hline & $\mathrm{R}^{2}$ & $\mathrm{~F}$ & Df1 & Df2 & Sig. & \multicolumn{2}{|c|}{ Constantb1 } & $\mathrm{b}$ & $\mathrm{R}^{2}$ & $\mathrm{~F}$ & Df1 & Df2 & \\
\hline Linear & 0.122 & 3.060 & 1 & 22 & 0.094 & 26.704 & 0.020 & & 0.594 & 32.240 & 1 & 22 & \\
\hline Quadra & iఠ. 277 & 4.024 & 2 & 21 & 0.033 & 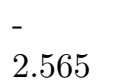 & 0.182 & & 0.613 & 16.650 & 2 & 21 & \\
\hline Power & 0.206 & 5.694 & 1 & 22 & 0.026 & 5.611 & 0.301 & & 0.545 & 26.391 & 1 & 22 & \\
\hline Expone & ttolal 50 & 3.886 & 1 & 22 & 0.061 & 25.451 & 0.001 & & 0.582 & 30.641 & 1 & 22 & \\
\hline
\end{tabular}

Table 2 Results of the curve estimation of the relationship between water additions and total biomass, aboveground biomass, belowground biomass and R: S ratio (i.e. the ratio of aboveground biomass and belowground biomass) of species Stipa grandis with linear, quadratic, power and exponential equations, where $\mathrm{R}^{2}, \mathrm{~F}$, Df1, Df2, significance, constant, b1 and b2 were showed. A larger $\mathrm{R}^{2}$ with a significant value is a better estimation, which is marked in red

Stipa

gran-

dis Total Total Total Total Total Total Total Total AbovegroAubdvegroAthdvegroAubdvegrodubd Equationbiomass biomass biomass biomass biomass biomass biomass biomass biomass biomass biomass biomass biom

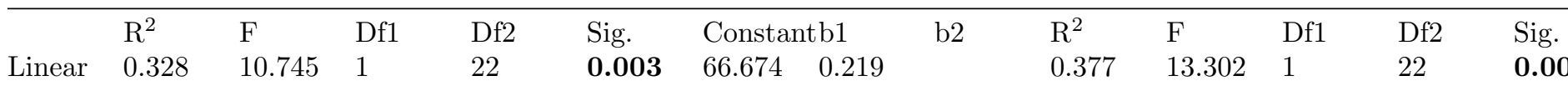




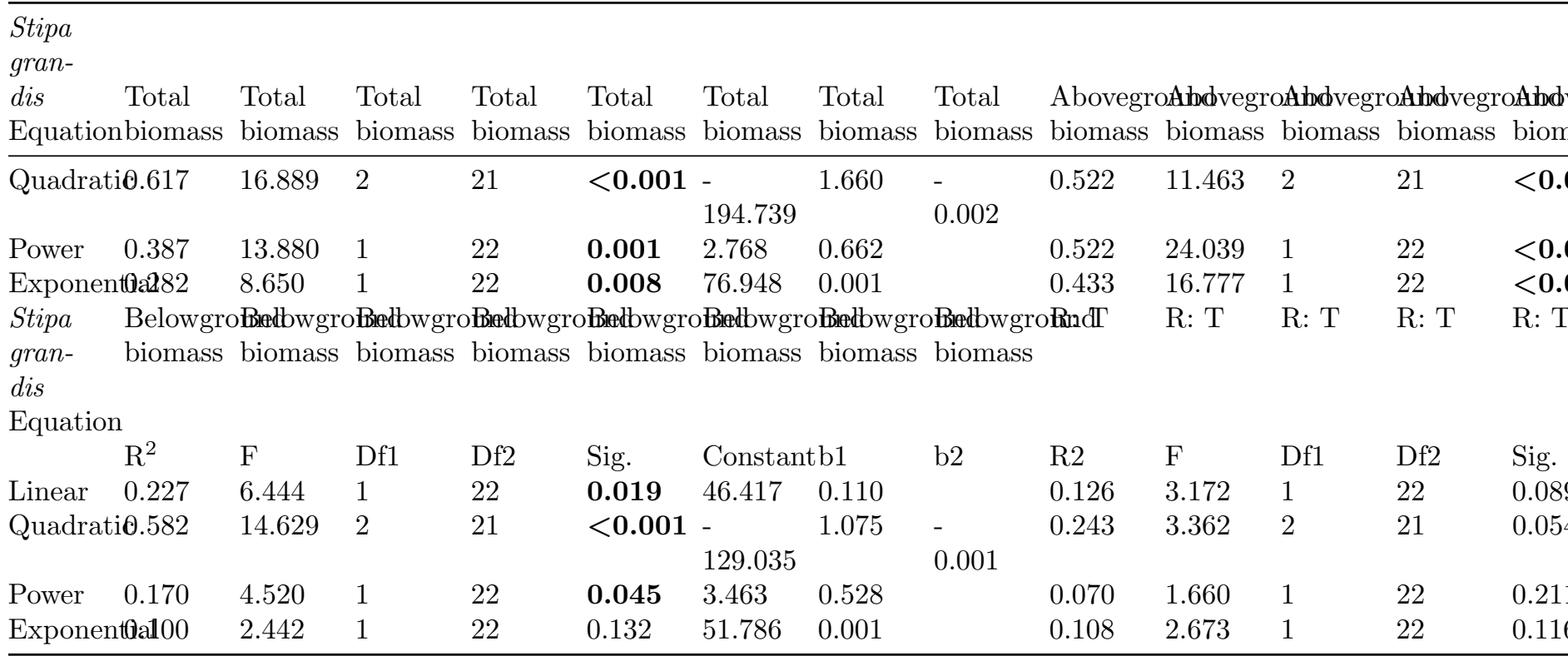

Table 3 Results of the curve estimation of the relationship between water additions and total biomass, aboveground biomass, belowground biomass and R: S ratio (i.e. the ratio of aboveground biomass and belowground biomass) of species Artemisia frigidawith linear, quadratic, power and exponential equations, where $\mathrm{R}^{2}$, F, Df1, Df2, significance, constant, b1 and b2 were showed. A larger $\mathrm{R}^{2}$ with a significant value is a better estimation, which is marked in red

Artemisia

frigida Total Total Total Total Total Total Total Total AbovegroAubdvegroAubdvegroAubdvegroAbd Equationbiomass biomass biomass biomass biomass biomass biomass biomass biomass biomass biomass biomass biom

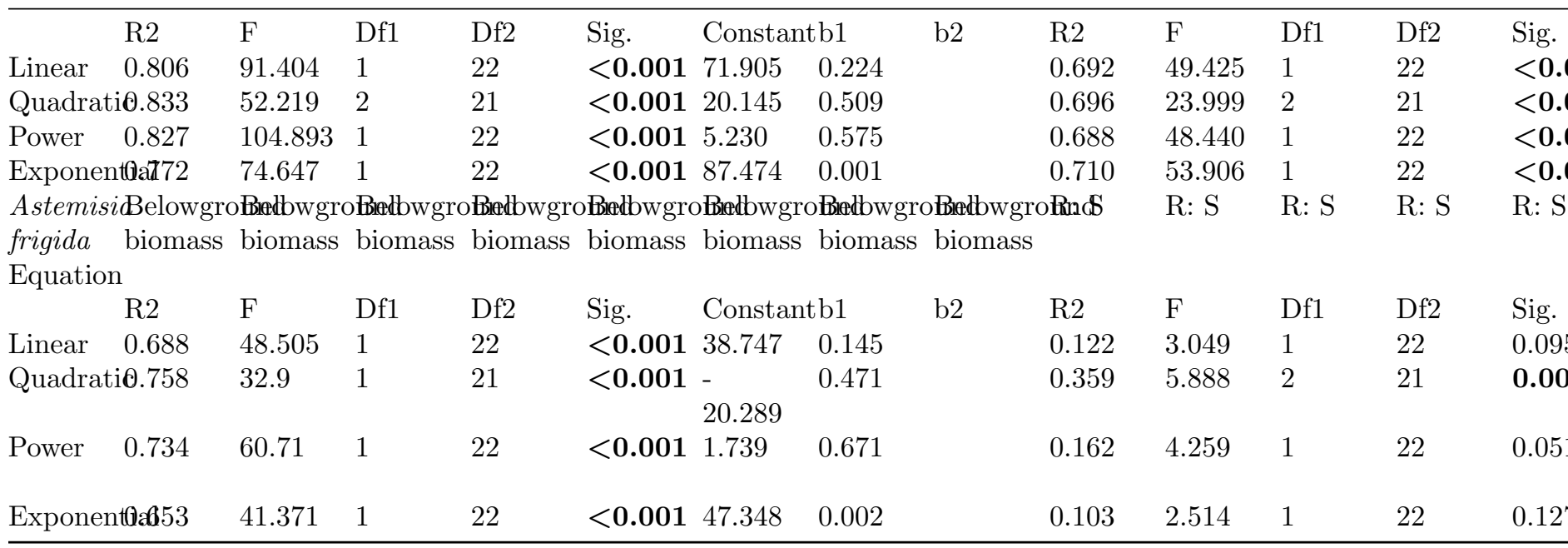

Table 4 Results of the curve estimation of the relationship between water additions and total biomass, aboveground biomass, belowground biomass and R: S ratio (i.e. the ratio of aboveground biomass and belowground biomass) of species Potentila acauliswith linear, quadratic, power and exponential equations, where $\mathrm{R}^{2}$, F, Df1, Df2, significance, constant, b1 and b2 were showed. A larger $\mathrm{R}^{2}$ with a significant value is a better estimation, which is marked in red 


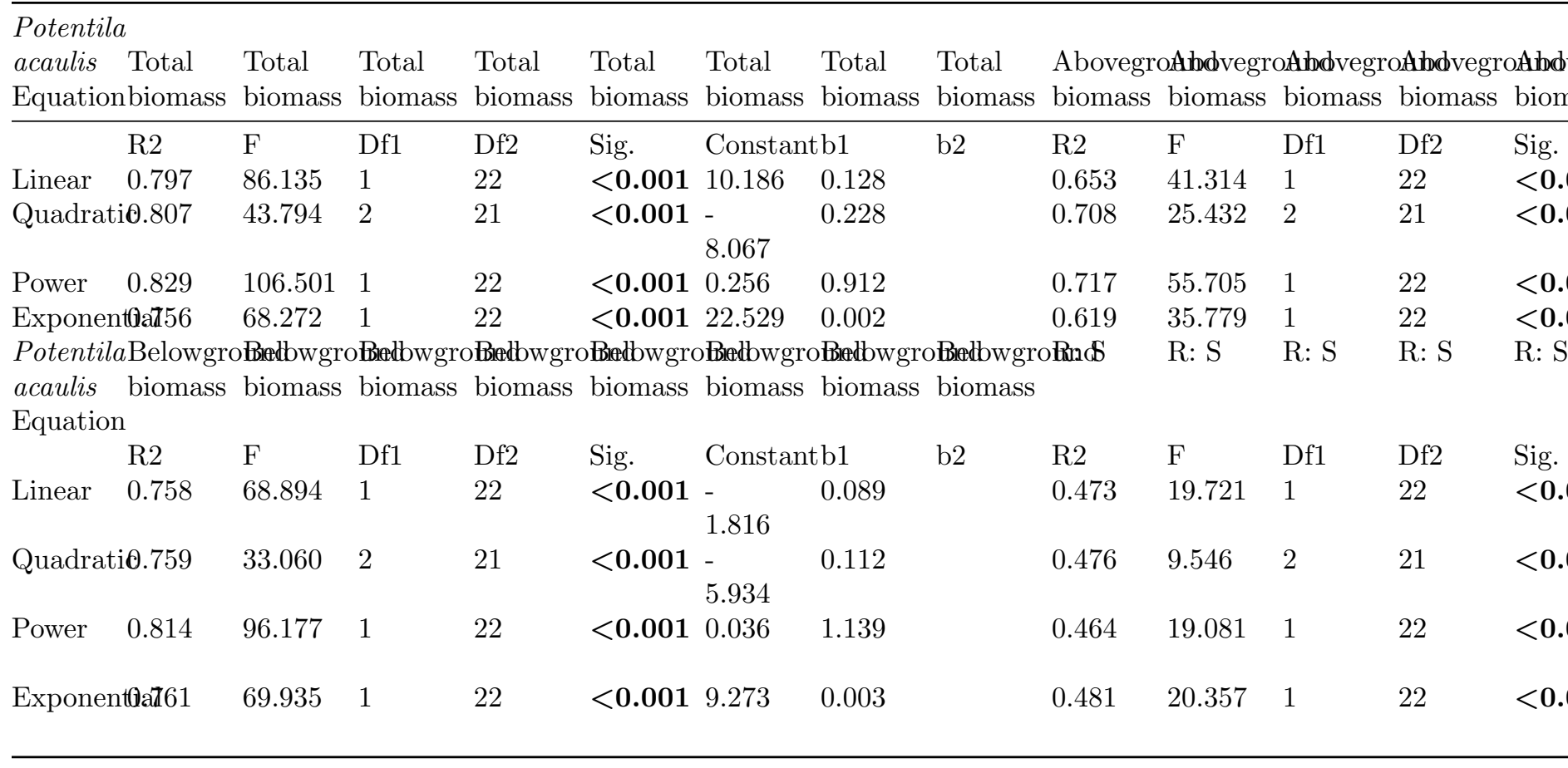

Figure 1 The experimental field

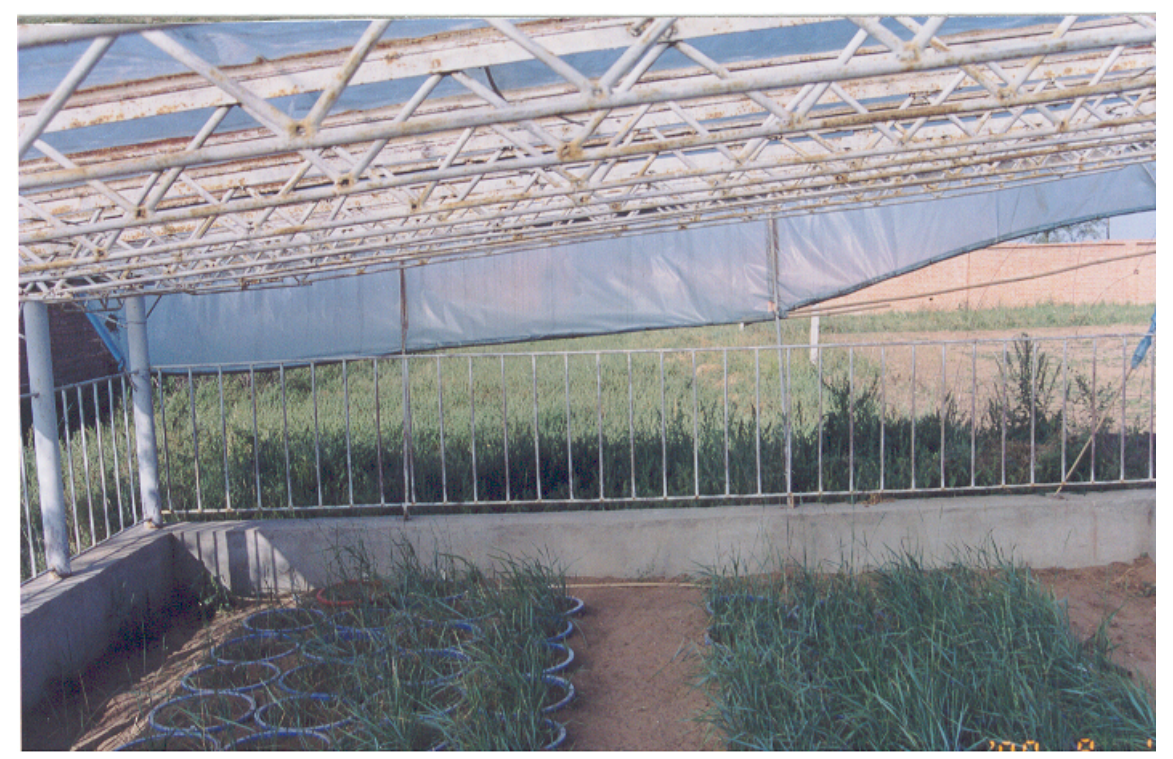

Figure 2 Non-liner regressions between water additions and total biomass, separately for Leymus chinensis (a), Stipa grandis (b), Artemisia frigida (c) and Potentila acaulis(d), where estimation equation, $\mathrm{R}^{2}$ and the significance are given 

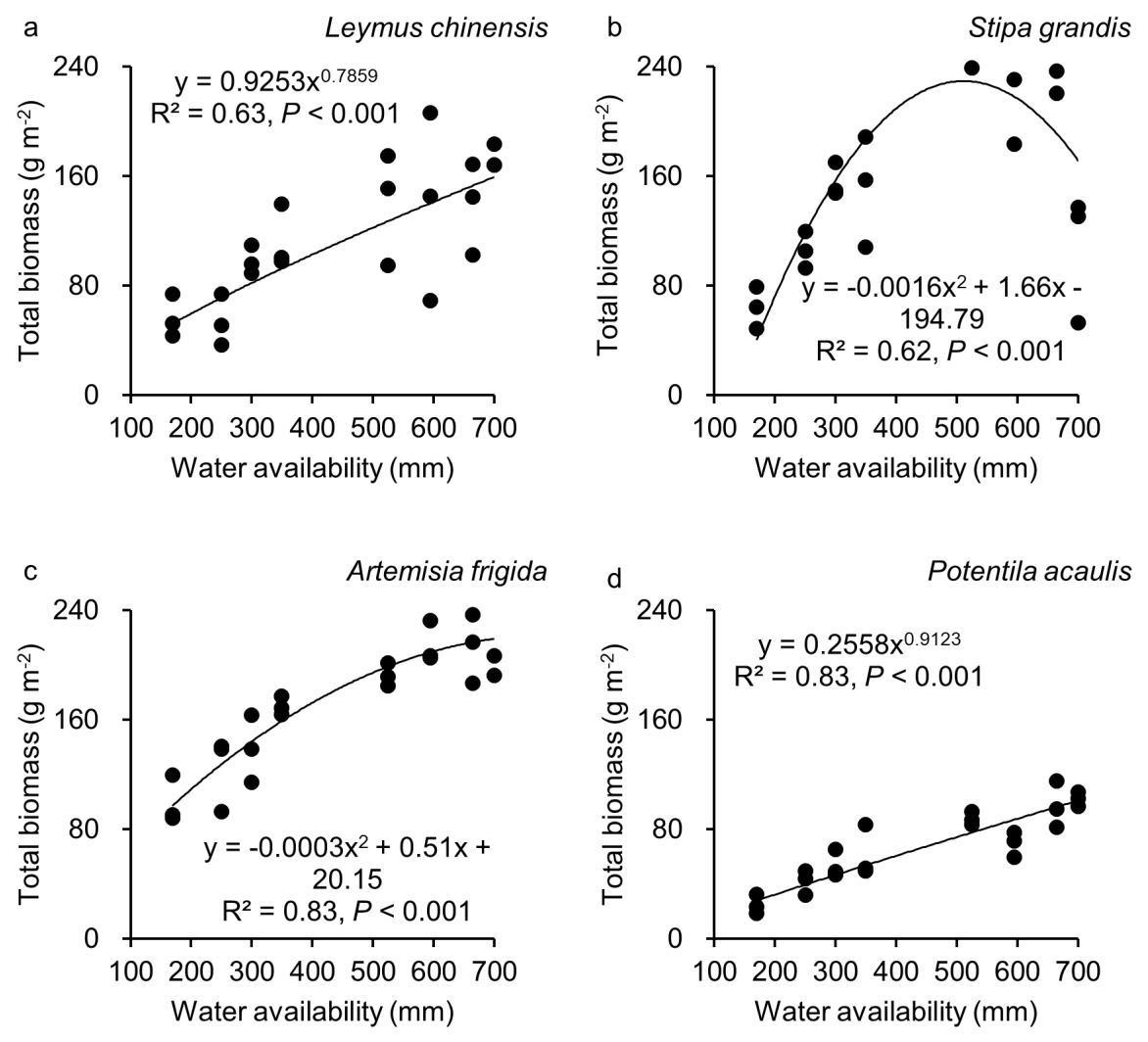

Figure 3 Non-linear regressions between water additions and aboveground biomass, separately for Leymus chinensis (a),Stipa grandis (b), Artemisia frigida (c) andPotentila acaulis (d), where estimation equation, $\mathrm{R}^{2}$ and the significance are given 

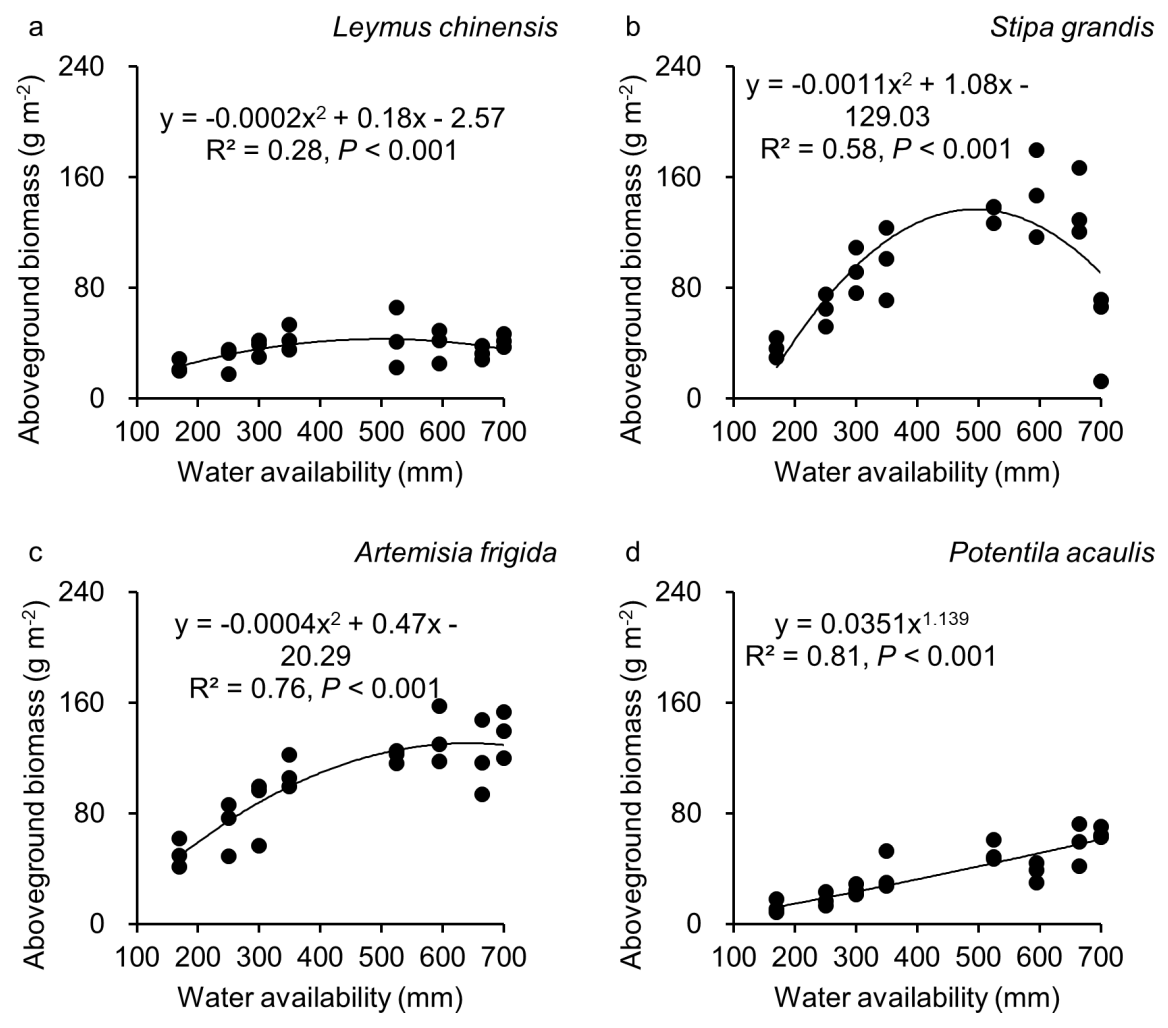

Figure 4 Non-linear regressions between water availability and belowground biomass, separately for Leymus chinensis (a),Stipa grandis (b), Artemisia frigida (c) andPotentila acaulis (d), where estimation equation, $\mathrm{R}^{2}$ and the significance are given 

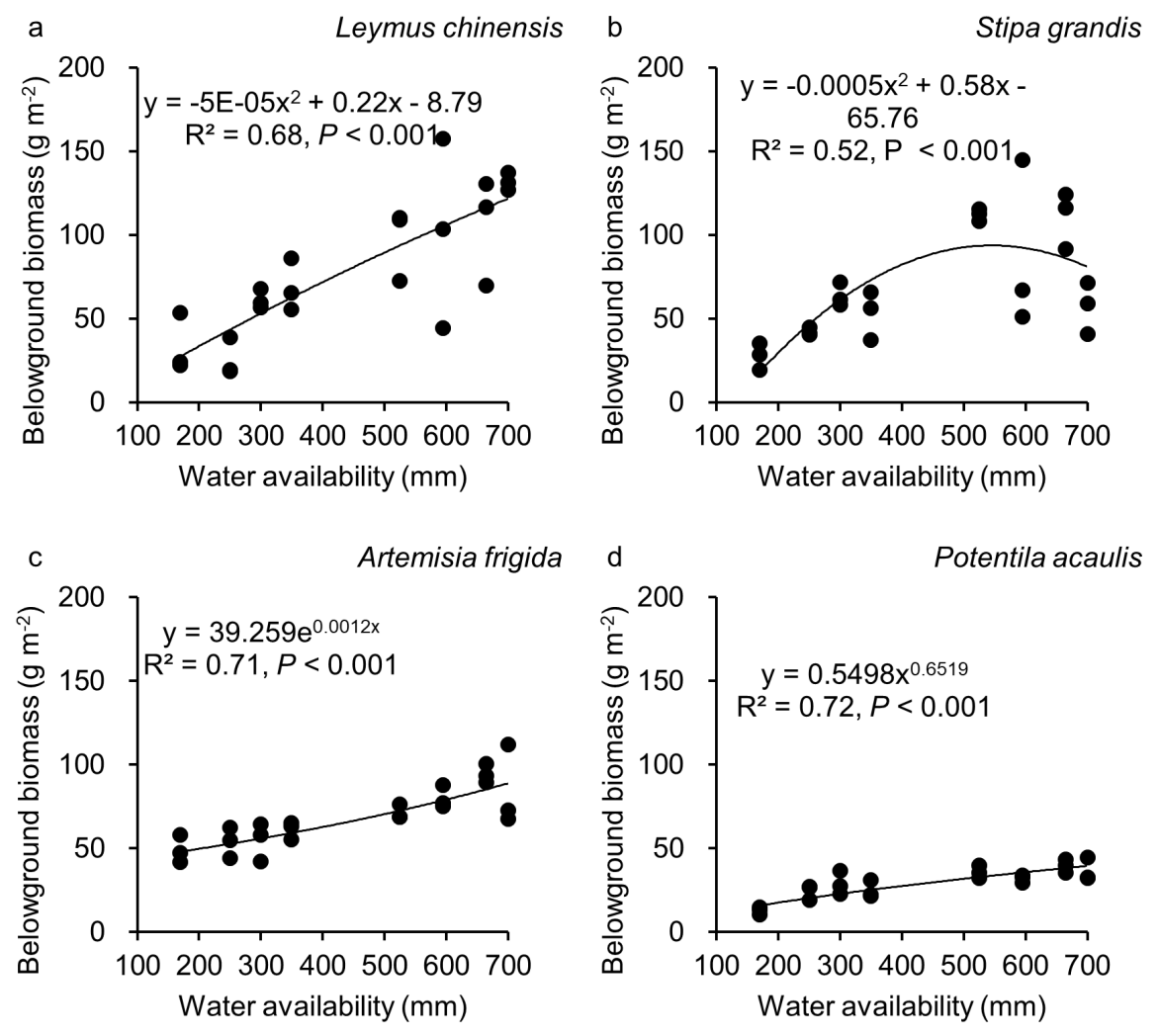

Figure 5 Non-linear regressions between water availability and R: S (i.e. the ratio of belowground biomass and aboveground biomass), separately for Leymus chinensis (a), Stipa grandis (b),Artemisia frigida (c) and Potentila acaulis (d), where estimation equation, $\mathrm{R}^{2}$ and the significance are given 
a

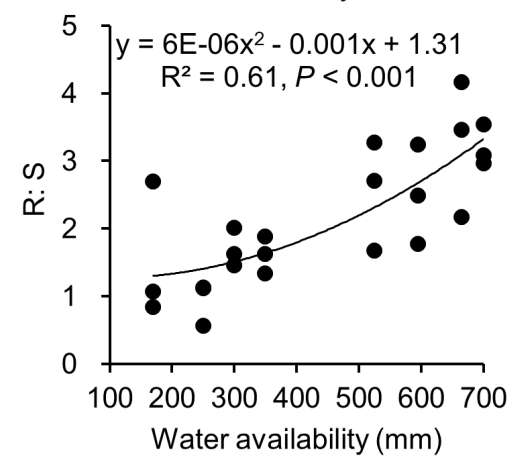

C

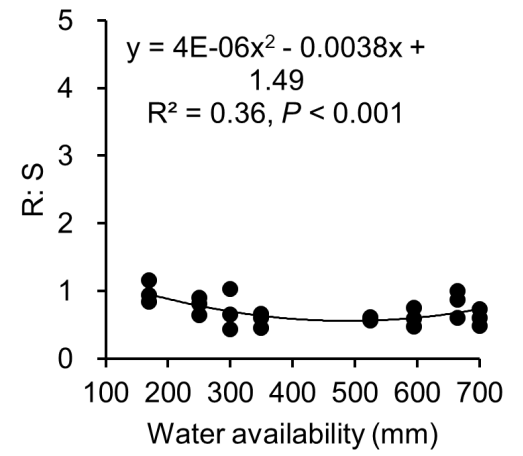

b

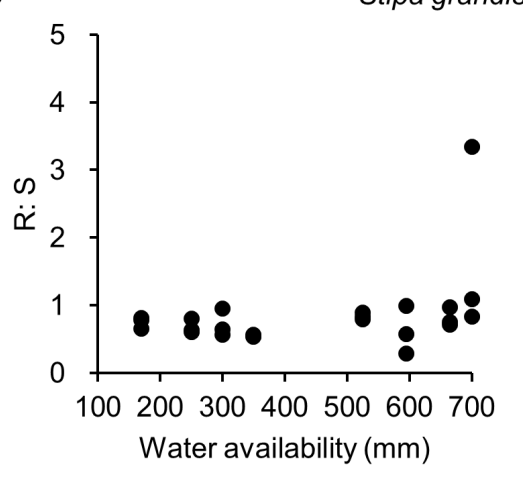

d

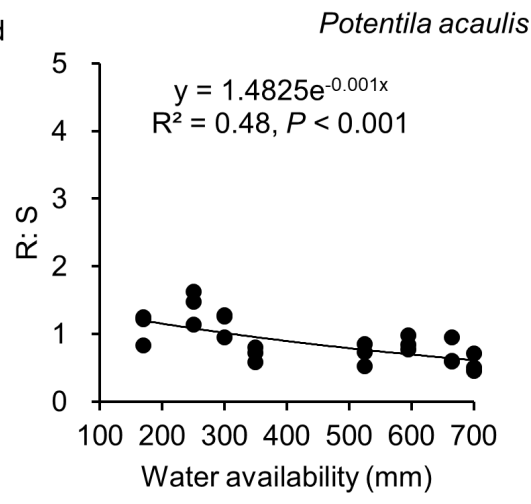

